\title{
UNA MIRADA FILOSÓFICA A LA FELICIDAD Y AL PERDÓN. UNA CONVERSACIÓN CON EL PROFESOR DIEGO SEBASTIÁN GARROCHO SALCEDO
}

Diego Sebastián Garrocho Salcedo Jennifer Natalia Mendoza Ariza 
Filosofía UIS, Volumen 14, Número 2

julio - diciembre de 2015 pp. 281 - 293

Escuela de Filosofía - UIS

\title{
UNA MIRADA FILOSÓFICA A LA FELICIDAD Y AL PERDÓN. UNA CONVERSACIÓN CON EL PROFESOR DIEGO SEBASTIÁN GARROCHO SALCEDO
}

\begin{abstract}
Resumen: las siguientes páginas presentan una reflexión en torno a cuestiones como el perdón, la felicidad, el papel de la Filosofía y las humanidades en la educación, así como el rol de la Filosofía en el análisis y cuestionamiento de las condiciones socio-políticas en las que se debe ejercer la ciudadanía actualmente.

Palabras clave: perdón, felicidad, imperdonable, investigación, ética.

\section{THE PHILOSOPHICAL PERSPECTIVES ABOUT HAPPINESS AND FORGIVENESS. A CONVERSATION WITH THE PROFESSOR DIEGO SEBASTIÁN GARROCHO SALCEDO}

\begin{abstract}
This paper offer a reflection about some problematic topics like forgiveness, happiness, the role of the philosophy and humanities in the education field, as well as the philosophy impact on the analysis and critic of the social and political conditions that humanity needs for practice the citizenship.
\end{abstract}

Keywords: Forgiveness, happiness, unforgivable, philosophical inquiry, ethics.

Fecha de recepción: octubre 28 de 2015

Fecha de aceptación: noviembre 18 de 2015

Forma de citar: Garrocho, D. y Mendoza, J. (2015). "Una mirada filosófica a la felicidad y al perdón. Una conversación con el profesor Diego Sebastián Garrocho Salcedo". Revista Filosofía UIS. Volumen 14, (2). pp. 281-293.

Diego Sebastián Garrocho Salcedo: español. Doctor Internacional en Filosofía de la Universidad Autónoma de Madrid. Profesor Universidad Autónoma de Madrid.

Correo electrónico: garrocho.salcedo@gmail.com

Jennifer Natalia Mendoza Ariza: colombiana. Magíster en Filosofía, Universidad Industrial de Santander. Profesora Universidad Industrial de Santander y Asistente editorial de la Revista Filosofía UIS.

Correo electrónico: revistafilosofia@uis.edu.co

* Entrevista. 


\section{UNA MIRADA FILOSÓfICA A LA FELICIDAD Y EL PERDÓN. UNA CONUERSACIÓN CON EL PROFESOR DIEGO SEBASTIÁN GARROCHO SALCEDO}

Natalia Mendoza: ¿En qué área o tema específico se centra su trabajo de investigación actualmente?

Diego Sebastián Garrocho Salcedo: Con respecto a mi investigación actual, suelo mantener una doble preocupación. Por un lado, siempre voy a tener una mirada puesta en Grecia. Mis primeras investigaciones, mi tesis doctoral, mis primeros trabajos tenían que ver con la ética griega y con Aristóteles. Pero, poco a poco, no sé si traicionándome a mí mismo, haciendo virtud de esa deslealtad, mis preocupaciones se han ido trasladando a otras áreas de la Filosofía, incluso a algunas de las que había renegado cuando era joven, cuando era estudiante.

Ahora, en términos materiales, lo próximo que haré va a ser una traducción de Derrida, un texto llamado Perdonar lo imperdonable y lo imprescriptible, un largo epílogo epistolar un tanto extraño. Además, estoy escribiendo sobre una de mis obsesiones, porque cuando la inspiración es muy poca, como en mi caso, solo suelo confiar en las obsesiones. Y una de mis obsesiones vitales es la nostalgia, esa experiencia del tiempo pasado que vuelve en forma de dolor. Un dolor que puede ser soportable o insoportable, fecundo e infecundo. Por esto, con Jesús Cano Reyes, de la Universidad Complutense de Madrid, estamos escribiendo un ensayo sobre la nostalgia.

NM: ¿Qué relación hay entre desenvolverse profesionalmente como investigador y el ejercicio de la filosofía?

DSGS: Para mí esto es una opción entre otras, es indistinguible. Cuando decidí estudiar filosofía y eso no tiene que ver con ser filósofo; cuando decidí hacerme profesor, mi única vocación era el aula, era la práctica docente; pues, 
no concibo pasar horas en una biblioteca desentrañando el sentido oculto de un texto o profundizando en un detalle, que puede ser más o menos banal, si no es con vistas de mejorar mi práctica educativa, para tratar de mentir lo menos posible a mis alumnos. Ahora, mi vocación laboral es muy distinta a mi vocación existencial. Mi vocación laboral es estrictamente docente. Por esa razón, siempre he interpretado la investigación como una actividad al servicio de la docencia para tratar de dar mejores clases. Es verdad que cuando uno no es especialmente brillante tiene que copiar a la gente genial. Entonces, uno a veces al investigar se sorprende y se permite copiar a la gente; porque encuentra una frase que motiva, una excusa para suplir las carencias y sobretodo servirse de las cosas que han hecho los grandes de verdad.

NM: ¿Qué papel desempeña el filósofo investigador en la sociedad actual? Teniendo en cuenta que las humanidades están siendo relegadas al olvido o a la virtualidad en los programas académicos. Por ejemplo, los profesores de educación secundaria de nuestro país han realizado reuniones precisamente en protesta por ese encasillamiento de las humanidades. Al igual que varios profesores universitarios, adscritos a las humanidades, quienes el 2 de octubre de 2015 se reunieron en la Universidad del Valle, donde alzaron su voz para protestar ante la desaparición paulatina de las humanidades en pro de la investigación y el conocimiento centrado en la innovación tecnológica.

DSGS: Este tema es pertinente y a la vez de una relevancia importantísima. Sobre este asunto siempre recuerdo las palabras de Husserl, quien decía que una ciencia de hechos nos volverá una humanidad de hechos. Creo que socialmente basta con echarle una mirada al mundo para ver que hay algo que no va bien. Hay muchas cosas que empiezan a ir mal y es responsabilidad de los políticos, quienes deberían ser personas que nos guían para mejorar y reparar las fallas, pero no lo están haciendo. En España estamos en las mismas circunstancias: con la última ley de educación, la Filosofía se ha relegado a un segundo lugar. Frente a esto hemos intentado protestar, aunque no todo lo que deberíamos y socialmente se ha aceptado esta transformación de los estudios. Todo esto es una vieja querella, ya que interpretar los currícula educativos es una decisión estrictamente política, creo que no hay nada más político que la decisión de establecer qué contenidos deben estudiarse, qué debe conocerse. Esto acaba por traducirse en algo así como qué es la verdad. Además, en Filosofía Política no hay que ser un foucaultiano para entender que efectivamente esa relación es una relación prioritaria.

Por ende, me da mucha pena, porque con esto estamos demostrando que no sabemos aprender de la historia. Cuando uno mira el éxito de la filosofía de la Francia de la segunda mitad del siglo XX, uno puede pensar que la prosperidad fue espontánea. Incluso, puede pensar que la prosperidad de la república francesa, que para muchos es un modelo estatal, no tiene nada que ver con esa filosofía. En ese sentido, debemos creer que si existió Sartre, Camus, si existieron después 
Foucault, Deleuze, Derrida tuvieron mucho que ver, y sobre todo estos tres últimos nombres, con la estructuración y la institucionalización de la filosofía en aquella Francia, donde la filosofía siempre ha tenido una presencia preferencial dentro del currículo de bachillerato, en las instituciones y liceos, donde se permitía la preparación de los exámenes de ingreso al École Normale, fueron estas instituciones las que estructuraron aquellas mentes y formaron el ethos e hicieron posible que hoy Francia tenga filósofos en la lista de los más vendidos. Esto no es hacer una defensa gremial, sino reconocer que entender la experiencia humana exige necesariamente servirnos de los mejores, quienes están decantados por tradición, lo cual es problematizable, pues no hay que consagrar un canon.

Según lo expuesto, renunciar a las humanidades y a la Filosofía es algo que hoy en día se está pagando; dado que, como hacemos una lectura absolutamente ingenua sobre el progreso científico, observamos que hoy conocemos más que nunca, tenemos máxima capacidad para transformar la naturaleza, satisfacer nuestras necesidades y deseos; sin embargo, la tasa de felicidad en los países más desarrollados va decreciendo, es decir, sabemos más que nunca, pero somos más infelices que nunca. Entonces, o bien no estamos sabiendo lo que tenemos que saber o la promesa entre la prosperidad y el conocimiento es falsa. No obstante, sigo creyendo que el conocimiento trae prosperidad y nos ha de llevar a una forma de felicidad y satisfacción de la existencia, lo que me lleva a pensar que estamos aprendiendo las cosas que no merecen la pena ser conocidas o nos estamos concentrando en un área del conocimiento que no agota la problemática de la existencia humana.

NM: ¿Qué lo mueve a tratar el tema del perdón?

DSGS: La propia experiencia vital me ha llevado a pensar en el perdón como cuestión filosófica. Ahora, las distintas formulaciones del Imperativo Categórico kantiano pueden ser preocupaciones propicias para un curso de Filosofía Moral, pero es mucho más difícil llevar ese análisis a la experiencia vital. En cambio, el perdón es una cuestión que interesa al filósofo y al no filósofo, si se tiene en cuenta que todos hemos pedido perdón en algún momento de nuestras vidas, todos hemos perdonado y, a veces, hemos sentido inquietud ante determinados escenarios sobre sí debíamos o no perdonar. Mi preocupación por el perdón sí tenía que ver con esas infidelidades y partió de allí, como casi siempre de una inquietud, podríamos humanizarlo más, de un sufrimiento. Empecé a hablar de Derrida y su relación con el perdón, porque creo que, aunque seamos filósofos, podemos contravenir al principio de que todo tiene una causa. Para esto, podemos acudir a Aristóteles, quien habló del azar y el azar hace que un día uno diga una frase, luego esa frase le genere un interés específico. Esto me sucedió cuando leí a Derrida y renegaba de la filosofía derridiana, cuando era más analítico de lo que soy ahora, me interesaba el uso de la contradicción; incluso, a veces, me indignaba que un filósofo pudiera contradecirse en aquella lectura o interpretación 
tan ingenua que yo hacía de aquellos textos. Sin embargo, con Derrida me ocurrió que pensaba que no tenía ningún sentido lo que leía, pero no podía dejar de leer, entonces eso me permitió darle más tiempo y confiar en que aquella prosa tan extraña, en que aquel decir filosófico tan poco ortodoxo, tan poetizante, pero al mismo tiempo con ese aspecto de ser casi fraudulento llegó a retener mi atención. El caso del perdón me parece que es una ocasión paradigmática para la filosofía de Derrida. La tesis fuerte del texto que estoy traduciendo y que aparece en muchas otras obras de Derrida es que solo se puede perdonar lo imperdonable. Claro, si nosotros trazamos una exhortación a cualquier filósofo analítico dirá que eso no tiene ningún sentido y que es un absurdo. Pero se debe reconocer que lo absurdo tiene una significación, una significatividad filosófica. Entonces, comencé a tirar del hilo y a tirar de ese aparente oxímoron, de esa contradicción, de una contradicción que es también oval, ya que el perdón se exige pero si es imposible, parece impertinente que alguien te exija lo imposible. Este tema también evocaba una figuración de la idea de héroe que a mí siempre me ha interesado, desde pequeño tenía una fascinación con los héroes, incluso con los héroes clásicos, no simplemente con los súper héroes. Esto se ha trasladado a la ética que me ha interesado más allá de la pura prescripción de lo permitido y lo prohibido, al enfocarme en aquellos actos que estaban solo al alcance de algunos individuos que no son como yo. Yo leía en esa distancia, en esa admiración. Por eso algo como el perdón imposible, como perdonar lo imperdonable convocó mi atención y ahí seguimos.

La promesa en el perdón, ante el perjurio, es, por cierto, una vocación en la que uno hace posible o deja que trasparezca una tradición claramente judaizante o religiosa que en realidad habita en mi interés. Esto es una pista: yo solo me he atrevido a decir que podía entender algo de Derrida cuando introduje la clave del alma, de su trato con las palabras y su manera de pensar.

NM: ¿Cómo concibe el perdón en una sociedad marcada por una tendencia de desconocimiento al respeto fundamental por la diferencia? (Mujeres, grupos religiosos, inmigrantes, personas que desean exponer su disconformidad de género, entre otras categorías de personas que se ven expuestas a la vulnerabilidad que supone la violencia generalizada).

DSGS: Hay que establecer una diferencia entre lo que es la experiencia política del perdón y la experiencia personal del perdón. La experiencia jurídico-política del perdón, como la amnistía, el indulto, la prescriptividad de los delitos las apartaría y creo que deben tratarse en otra escena en donde no se podría justificar esta exigencia de perdonar lo imperdonable. Primero, porque no se podría exigir jurídicamente $y$, segundo, porque si nosotros desatentemos las formas clásicas de la justicia transicional, la reparación del daño, la atención a la víctima en nombre de un perdón político de esta forma estaríamos generando una injusticia. 
En cambio, está la ética hiperbólica, denominada así por Derrida y Jankélévitch, la cual tiene que ver con la experiencia singularísima y personal del perdón, y esto lo quiero subrayar, ya que solo se puede perdonar el daño que se infringe sobre la propia persona, pues uno no puede perdonar el perjuicio que se ha generado sobre otro, en otras palabras, uno solo estaría dispuesto a expresar esa máxima generosidad o esa experiencia límite cuando el que está hablando se refiere a un daño sufrido en primera persona. Si nosotros trasladamos esa experiencia a la escena política, el perdón superlativo probablemente ya entrañaría formas de justicia nada deseables y aquí es importante distinguir entre justicia y misericordia, porque la segunda es un término con una tradición judía, cristiana, que también es tratado por Derrida. Por otra parte, nuestra imagen de la justicia tradicional tiene una caracterización latina relacionada con el cálculo, la reparación y la ponderación, por eso nosotros nos imaginamos la justicia como una mujer con una balanza y los ojos vendados que está calculando exactamente el daño y cómo debe repararse. Por el contrario, la lógica del perdón superlativo no tiene nada que ver con esa ponderación y, por lo tanto, no sería trasladable al ámbito político.

En cuanto al concepto de diferencia, cabe pensar la distinción entre la filosofía y la experiencia de la diferencia en cuestiones políticas, porque si miramos en el contexto quien conoció la diferencia política fue Derrida, uno de los padres, junto con Deleuze, de la caracterización contemporánea de este concepto. Por nombrarlo de algún modo, podríamos subrayar esa evocación religiosa de que la filosofía nace desde la experiencia del perdón. Si nosotros vamos a las últimas páginas de la Apología de Platón, Sócrates termina perdonando, y precisamente termina perdonando haciendo uso de una invulnerabilidad propia del hombre que lleva a cabo una vida teórica, que sabe que el peor mal que puede acechar al hombre no es sufrir una injusticia sino cometerla, en una descripción socrática siempre seremos invulnerables si nos concentramos por vivir una vida sometida a examen y a la virtud.

NM: Sí, precisamente pretendía que pudiéramos hacer esa salvedad porque como sociedad estamos atravesando por un proceso bastante coyuntural y esa falta de discernimiento acerca de esos dos niveles: todo lo que tiene que ver con la ley y los términos que se ajustan a la reparación generan procesos distintos de perdón y de reparación entre los procesos individuales, entre las poblaciones que han sido afectadas por los grupos implicados en el conflicto. Pero, también me preocupa un poco mirar si es posible partir de esa experiencia tan particular y cómo podría construirse un perdón y pongo como ejemplo las desapariciones. Hay un asunto interesante y es que en las situaciones de violencia exacerbadas, por las razones que sean, se desaparecen los cuerpos, no se les nombra y ahí me surge la pregunta acerca de cómo podría darse ese perdón y quién tendría derecho a saber o a decir qué se hace con esos muertos. 
DSGS: Quiero subrayar la diferencia entre la experiencia personal, la experiencia política y la experiencia verdaderamente exigible. En el ámbito político nada de lo dicho hasta el momento puede tener cabida. Soy consciente de que ustedes se encuentran a las puertas de un momento transicional, un momento de reparación del conflicto político, que para mí como español no me es completamente ajeno, porque hemos vivido dos circunstancias que no son exactamente iguales, pero sí se parecen. España vivió un proceso de amnistía, la transición de la dictadura franquista hacia la democracia y nosotros también llevamos ahora unos años en los que la violencia de la banda terrorista ETA ha cesado y donde también en el País Vasco se está haciendo un debate social acerca de cómo debería gestionarse políticamente ese daño. Un daño que reivindica las partes, pensado, en ocasiones, como un conflicto simétrico. Desde luego que, para mí, no es un asunto simétrico. Esta es una problemática muy difícil para la que no tengo solución y sobre todo sospecho de aquellos que tengan soluciones rotundas. Por esta razón, creo que cada uno de esos escenarios debe atenderse con sumo cuidado, probablemente no exista análisis del debate, no se trate simplemente de decidir cuál puede ser la solución más óptima, sino también la solución que la sociedad esté dispuesta a asumir. No podemos concebir que exista un político absolutamente virtuoso que dé con la clave, si después socialmente no hay orientación, porque puede darse en falso los procesos. Para vergüenza nuestra, en España, se sigue debatiendo si deben o no desenterrarse las fosas comunes de aquellos enterrados sin nombre. Esto es importante, dado que quitar los nombres es otra forma de matar a alguien, si se tiene en cuenta que los griegos llamaban sema a la tumba, porque era el lugar donde se escribía el nombre; además, olvidar el nombre es la peor forma de olvidar a alguien. Aquiles sabía que era mortal y por eso aspiraba a que se recodara su nombre. Vivir en el nombre es una forma de existencia, de persistencia, que debe siempre respetarse y promocionarse. Creo que son cuestiones muy complicadas, no tengo solución y me temo que nadie la tiene.

NM: En ese orden de ideas, ¿qué tipo de relación se puede observar entre el olvido y el perdón?

DSGS: Cuando uno piensa en su experiencia doméstica del perdón, normalmente lo vincula al olvido. Por ejemplo, hay un lema que dice ni olvido ni perdón. En España suele decirse yo perdono, pero no olvido. Es curioso que en inglés haya una relación entre forget and forgive, and get and give, en principio parecen contrarios, pero se vinculan en las acciones de dar y recibir. Me gustaría dar un paso más allá y generar una exigencia del no olvido, para que la experiencia verdadera del perdón se mantenga siempre vigente. El olvido es un estado de conciencia ausente, es decir, si nosotros equiparamos el olvido y el perdón, incluso un olvido inconsciente, un fallo cognitivo, podría asimilarse a una experiencia moral y yo no lo creo. El concepto radical de perdón se puede llevar hasta las últimas consecuencias, pues creo que no habría un perdón más perfecto 
que aquel perdón que no olvida y no permite repetir lo pasado. Un perdón que recuerde y en ese recuerdo, en esa memoria sea capaz de persistir, porque si he olvidado algo ya no puedo perdonarlo, perdonarlo es ser capaz de recordarlo, ser capaz de mirar frente a frente el acontecimiento y decir mantengo siempre mi perdón pese a eso, sería una cuestión muy bonita.

Ahora, si es o no revocable el perdón, si es un acontecimiento reversible o no reversible es otra cuestión. La palabra perdón es una palabra singularísima, es una de las pocas que dice lo que hace en casi cualquier lengua. Si digo elefante no aparece aquí un elefante, pero si digo perdón ya estoy pidiendo perdón, es decir, la propia enunciación ya está haciendo que acontezca esa experiencia que me parece que el perdón reclama. Pero también tendríamos que preguntarnos: ¿es revisable el perdón? o ¿el perdón es necesariamente irreversible? A mí no me gustaría vincular siempre el perdón al olvido; por el contrario, me gustaría ser capaz de recordar sabiendo que ese recuerdo adquiere una dosis de ficción narrativa no comprometida con la mentira, pero sí con la recreación que puede ser interesante.

NM: ¿Cuál es el rol de la palabra y la escucha respecto a la realización de la limitación propuesta por Derrida de perdonar lo imperdonable?

DSGM: Derrida aborda el tema del perdón anunciando que va a tratar una palabra. Derrida siempre habla de palabras, para él solo hay palabras. Con tantas cosas en Derrida se puede pensar que este tipo es un vanguardista trasnochado y que no está diciendo nada. Pero estamos entendiendo mal a Derrida si tomamos ese "todo son palabras" o, dicho de otro modo, ese "no hay fuera del texto" como algo literal. Así el texto es como la realidad, pues se comporta como el texto y por lo tanto no hay manera de pensar el perdón si no es pensando la palabra perdón. La singularidad de esta palabra es que hace lo que dice, se enuncia por cierto preferentemente de manera oral, aunque también evoca la posibilidad de pedir perdón a través de la escritura, en tanto se puede solicitar por escrito el perdón. No sé cuál sería el perdón más apto.

Convendría preguntarnos: ¿el perdón es una experiencia privada o es una experiencia pública? Curiosamente en términos jurídicos, en ocasiones, se exige pedir el perdón público, cuando probablemente la experiencia más íntima del perdón es aquella que se da cara a cara y es aquella que no requiere el testimonio, sino que se convierte en un acontecimiento puro custodiado por la observancia de esos dos protagonistas que son capaces de pedir perdón o de conceder el perdón. Porque creo que una de las cuestiones más bonitas es que el perdón en Derrida no es la respuesta a una petición, no trata de resolver una solicitud en la que alguien pide perdón, propiamente perdonar se experimenta cuando lo hacemos sin que nos lo pidan, sin que consigamos nada a cambio reduciéndolo a una privadísima experiencia. Es complejo, pero evocador. 
NM: Sobre su segunda conferencia que lleva por nombre "La relación cuerpomente en Aristóteles: las dificultades del Hilemorfismo" me gustaría plantearle dos cuestiones. La primera es desde su perspectiva y sus avances de investigación ipor qué el Hilemorfismo aristotélico presenta dificultades? Y de qué tipo son.

DSGS: En todos los manuales escolares sobre Aristóteles trata de resolverse la relación entre el alma y el cuerpo a partir de la relación entre la forma y la materia. Bueno, esto es falso porque Aristóteles no existe, existen muchos Aristóteles. El Aristóteles de juventud que al parecer hemos perdido, el Aristóteles maduro y el Aristóteles post-De anima que efectivamente concibe la relación entre el cuerpo y el alma como la de forma y materia. Esta relación no se da siempre en la obra de Aristóteles.

Mi preocupación, o lo que quería traer a debate, es vincular la relación entre el cuerpo y el alma con la razón y las pasiones. De nuevo, la tentación inmediata a la hora de trazar con una brocha muy gruesa la comprensión de la razón y de las pasiones en el mundo griego nos lleva, efectivamente, a relacionar el alma con la razón y el cuerpo con las pasiones. Se trata de un caso paradigmático, si se observa que la repartición del alma también se da en Aristóteles. Yo trataré de justificar por qué la distinción entre razón y pasión, entre logos y pathos, es mucho más impermeable en Aristóteles de lo que pareciera y cómo la relación entre cuerpo y alma está mucho más coordinada o constitutiva de lo que se sostiene en la tradición más platonizante que aristotelizante, puesto que es incomprensible cualquier experiencia sin el cuerpo. Aristóteles dice: el alma no hace, ni padece nada sin el cuerpo. Entonces, trataré de capitalizar esos rastros que no han resultado tan obvios en la apropiación tanto clásica como contemporánea de la obra de Aristóteles y a partir de ahí veré algunas paradojas relativas a las pasiones.

NM: ¿Qué papel tienen las emociones en esa relación cuerpo-mente, presente en la filosofía aristotélica y en torno a la que usted reflexiona?

DSGD: Una cuestión es la relación de las pasiones respecto al cuerpo y la mente y otra su función en el seno de la ética. Lo más relevante es el vínculo que existe entre la racionalidad y la disposición pasional en Aristóteles, no por el gesto ingenuo de decir que Aristóteles es el predecesor de teorías contemporáneas como la planteada por Lapesa, en donde se afirma que efectivamente las emociones no son más que reacciones ante un medio externo, causa de una forma de adecuación entre un estado pasional correcto y un estado de cosas correctas. Esto nos permite hablar de la intencionalidad, hoy diríamos, de las emociones en lugar de las pasiones, este aspecto se ve muy claramente con algunos ejemplos: nosotros podemos sentir una pasión como la ira de manera justa o de manera desajustada, como en el caso de que alguien sienta ira porque lo han mirado mal, claramente se presenta un problema de ajuste con la realidad; pero, razonablemente, alguien puede disponerse desde la ira cuando alguien le hace algo muy malo a un familiar. 
Entonces, en mi libro sobre Aristóteles, en uno de los capítulos, trato de explicar precisamente cómo el reconocimiento de los acontecimientos singulares, a partir de la inducción, exige, del mismo modo que cualquier acto cognitivo, una abstracción de esos casos singulares para poder disponer propiamente el alma a la hora de sentir pasiones. Me gustaría subrayar esa dimensión cognitiva que hace que se convoque también al nous, al intelecto, al entendimiento para operar esa forma de abstracción y concluir que también sintiendo nosotros conocemos cosas sobre nuestros sentimientos, como que pueden estar equivocados. Esta es la base de prácticas como el Psicoanálisis o cualquier forma de reversibilidad del estado emocional, si se tiene presente que alguien a través de la palabra o al mostrarnos la realidad es capaz de reconducir nuestro estado emocional es porque efectivamente nosotros sentimos una inclinación espontánea a ajustar nuestras emociones con el estado de cosas del mundo, diríamos desde una perspectiva muy realista.

El interés de las emociones para mí era claro y lo corroboraba con mi experiencia vital, es decir, yo no conozco a nadie, y si lo hubiera, me parecería una persona altamente peligrosa, que determine su acción a través del imperativo categórico de Kant, por ejemplo. O cualquier forma de racionamiento estrictamente moral o el silogismo práctico, por ejemplo. No conozco a nadie que tenga un dilema moral, un dilema moral real, porque muchas veces los filósofos morales nos equivocamos y siempre ponemos ejemplos de laboratorio muy absurdos, y no se tiene en cuenta que el talante moral del individuo se juega normalmente en escenarios mucho más inconcretos donde los matices son lo determinante y ahí creo que el racionamiento puro nos va a ayudar muy pocas veces o nos puede llevar a una paradoja moral y es que sabemos lo que hay que hacer, sin embargo no somos capaces de hacerlo, como demuestra la vieja paradoja en Ovidio, que aparece en las Metamorfosis, de ser capaz de reconocer qué es lo que está bien, pero ser incapaces de hacerlo. Esta transición entre lo que serían las ciencias teóricas que se agotan en el momento y que conocemos una solución, en términos de esto es justo y hay que hacerlo; en contraste con las ciencias prácticas que nos exigen realizarlo a pesar de que no podemos realizarlo. Es ahí cuando las emociones juegan un papel determinante y cumplen su función motivadora. De hecho, si nosotros decimos la palabra emoción en castellano estamos apelando a esa motivación, a ese motus en latín, a esa puesta en movimiento. Entonces, de lo que se trata es de cómo poder ordenar los deseos, las emociones y las pasiones para convertirnos en algo mejor de lo que somos y educarnos sentimentalmente, al respecto hay toda una tradición de la educación.

NM: Para finalizar, me gustaría poner en consideración de todos los asistentes un par de cuestiones acerca del tema propuesto para esta tarde: la felicidad y su conquista en el espacio político a la luz de la Ética a Nicómaco. La primera es ¿cómo puede el ciudadano conseguir la felicidad en la polis?, es decir, ¿cuál sería la dimensión práctica de la felicidad? y la segunda tiene que ver con hacer 
el ejercicio, por lo menos mental, de pensar si en las condiciones actuales el ciudadano o el individuo cuenta con las condiciones fundamentales para alcanzar la felicidad propuesta por Aristóteles.

DSGM: Respecto a la primera ¿cómo conseguir la felicidad en la polis?, lo primero que puedo decir es no tengo respuesta. Pero para hablar de esto hay que acercarnos a la obra de Aristóteles y pensar qué tiene que ver la felicidad con la polis. Sobre esto, lo primero que hay que decir es que la felicidad es una experiencia política, porque es una experiencia específicamente humana que no vivencian ni los dioses, ni las bestias, ese es el primer rasgo, de la misma manera que la ciudad es el espacio que habitan los hombres.

El problema es que nosotros estamos forzados a traducir y aunque lo digamos en griego nunca vamos a ser capaces de evocar el sentido original con el que los griegos usaban eudaimonia, que probablemente adquiera una serie de matices que se nos escapen. Al mismo tiempo, hay que reconocer que no sabemos interpretar el término político, porque si yo hablo de la felicidad como un estado político inicialmente podemos pensar en la polis como un espacio urbano, que los latinos llamaban urbs, esto implicaría que si estoy en Bucaramanga y camino en una dirección recta habrá un momento en el que ya no esté en la ciudad y si soy feliz en dicha ciudad, una vez salga de ella ya no podría serlo. Ahora, estoy seguro de que Aristóteles no era tan ingenuo, es decir, la polis puede adquirir muchas definiciones. Pero el énfasis que se lee en Aristóteles tiene relación con que no se puede ser feliz solo, algo tan sencillo como eso, es decir, la amistad, la philia o el amor tienen que ver con la felicidad, entendida como una experiencia que nunca puede ser privada. Como se puede interpretar a partir del libro $X$ de la Ética a Nicómaco, en donde se plantea la posibilidad de que un hombre viva una vida estrictamente teórica, estrictamente contemplativa, pero si se dan cuenta Aristóteles ni siquiera concluye que eso sea cierto, pues hasta el hombre consagrado a dios requiere la presencia de amigos. Entonces, creo que lo primero que podemos capitalizar es comprender que el hombre no puede ser feliz solo y esto contraviene todos los discursos contemporáneos de la independencia, del self made man, de la autocapacitación, de la autoafirmación en la vida, con las que la colección de experiencias que podemos procurarnos es muy poca. Creo que si empezamos confesando eso, ganaríamos algo a la hora de hablar de política. Al mismo tiempo, si asumimos que los afectos tienen que ver con la felicidad y que necesitamos ser queridos, empezamos a resolver parte del paisaje.

En lo que atañe a la distinción entre el amante y el amado en el mundo griego, Aristóteles decía que lo importante era amar, no ser amado; de la misma manera que lo importante era conocer, no ser conocido. En este sentido, lo importante sería conocer y generar un espacio donde pudiéramos querernos mejor, pero muchas veces lo olvidamos y pensamos que la política tiene que ver con la posibilidad de educarse y con la capacidad de acudir a un centro médico, 
se tengan o no, posibles tratamientos. Desde luego, esto es importante, pero también la política tiene que ver con experiencias mucho más íntimas de la vida y con las condiciones de posibilidad de establecer relaciones afectivas y amatorias en el sentido estrictamente erótico. Es decir, no estoy seguro de que nosotros estemos hoy construyendo un espacio político especialmente apto para formas prósperas de esa salud afectiva para que podamos queremos mejor, atenuando la objetividad sexual y afectiva que nos rige. Este es un caso que habría que estudiar con muchísimo detenimiento, pero creo que estamos conquistando cuotas de tolerancia, y la tolerancia está bien, en cuanto permite que las cosas acontezcan. También, a lo mejor, tenemos que preocuparnos si podemos ayudarnos a la hora de estructurar o de habilitar nuevas posibilidades para la gente con preferencias diversas en un mundo urbano que me parece contrario, porque se observa que somos infelices. Por ello, pienso que si estuviéramos en condiciones de querernos más y mejor nos haríamos muy felices, de eso estoy convencido, pero algo pasa y a lo mejor no es solo culpa nuestra $\Phi$

\section{REFERENCIAS}

Aristóteles (2014). Ética a Nicómaco. Madrid: Gredos.

Derrida, J. (2015). Perdonar lo imperdonable y lo imprescriptible. Madrid: Avarigani Editores.

Platón (2014). Apología de Sócrates. Madrid: RIALP. 